\title{
Analysis of Ring Yarn Properties Produced from Different Traveller Brands
}

\author{
Toufiqua Siddiqua, Assistant Professor \\ S. M. Farhana Iqbal, Associate Professor \\ Department of Yarn Engineering, Bangladesh University of Textiles, \\ Dhaka, Bangladesh
}

Doi: 10.19044/esj.2019.v15n18p53～URL:http://dx.doi.org/10.19044/esj.2019.v15n18p53

\begin{abstract}
A traveller is the tiny but significant part in ring frame in a short staple spinning mill. It is a small portion among all the parts of ring machine. It performs two most significant tasks like twisting without which spun yarn production cannot be imagined, and it aids in the winding of yarn on the cop. The traveller is one of the mechanical reasons for the hairiness properties of yarn. Two yarn of 30's Ne KH (Card hosiery) was produced by using two same number of the traveller of different brands called Lakshmi Ring Travellers (LRT) and X-AXIS. All the processing parameters remained the same during the production of yarn. After that, Uster Evenness Tester 5 machine was used to determine the yarn properties such as unevenness percentage, imperfection index, hairiness, standard deviation of hairiness, standard deviation of hairiness in reference length 1 meter, and standard deviation of hairiness in reference length 3 meters. The end breakage rate was recorded through whole doff for the duration of the production of yarn in ring section. Statistical analysis used t-test to pair two samples to obtain the means for unevenness percentage, imperfection index, and hairiness. This was accomplished with Microsoft Excel 2013. Lakshmi Ring Travellers indicate better results than X-AXIS traveller. It can be decided from the t- test that there is no significant difference in unevenness and hairiness except imperfection index of two brands.
\end{abstract}

Keywords: Traveller, LRT, X-AXIS, t-test, Yarn properties

\section{Introduction}

The textile industry makes available job opportunities to millions (or even more) of people and this contributes to the manufacturing world. However, it is considered as the old style industry (Feng-Lei Zhou \& RongHua Gong, 2008, p.837-845). The payment of tax to the machine 
manufacturer is done for the production of more sophisticated and accurate technology for effective and economic benefit. As a result, completion is becoming faster nowadays (Lawrence, 2009, p.1). For apparel production, ring spinning system is well-thought-out as the leading spinning system (Zheng-Xue \& Xungai Wang, 2004, p.735-74). The reasons behind the domination of ring spinning system over other spinning systems are due to the fact that it is a flexible spinning system. Additionally, it has a range of fibre types and can be spun yarn at the finer end of the usable count range. The most significant feature is seen in the structure and properties of the yarn (Lawrence, 2010, p.22). The development of new spinning systems alternative to ring spinning system had been completed within late sixties and early seventies for the course and medium count range, high production, elimination of winding and roving, and familiarizing automation (Harish Jamburl, 2018, p.377-383). Hairiness properties of ring spun yarn require a certain amount of fibres protruding from the main body (Akshay Kumar, Ishtiaque \& Salhotra, 2003, p.15-21). One of the reasons for excessive hairiness in the yarn is as a result of an improper profile of traveller (Neeraj Niijjaawan \& Rasshmi Niijjaawan, 2010, p.423). “Traveller is a C-or Dshaped wire clip (made from good tempered steel) which fits loosely on the flange and races on its circular path by the yarn pull to introduce twists into the strand of fibres emerging from the front roller nip" (Pattabhiram, 1997, p.150). It is used as a guide of the yarn and was invented in the USA by Messrs (Eric Oxtoby, 1987, p.121). The two main tasks of traveller are to impart twists to the yarn and permits in winding the yarn on the bobbin (Klein, 2011-2012, p.203). The choice of the weight of the traveller is completed to control the winding tension which may make the lower balloon tension at the other side of the traveller. Balloon tension becomes less than half of the winding tension due to the yarn traveller friction. The rise of the spinning tension between the lappet and the front roller nip depends on the balloon tension (Eric Oxtoby, 1987, p.122). It does not have its own motion, and it is dragged along behind the spindle. The difference in speed between spindle and traveller helps to wind. The reason for the formation of large contact pressure (up to $35 \mathrm{~N} / \mathrm{mm} 2$ ) between the ring and the traveller in the period of winding is a centrifugal force. Strong frictional forces are induced by this pressure which causes generation of heat. The lightweight traveller cannot dissipate the generated heat quickly. Thus, this results in the limitation of the operating speed of traveller (Klein, 2011-2012, p.203).

\section{Materials and Method}

The fibre selected for this paper was CIS for the production of yarn. Properties of fibres were tested by using the High Volume Instrument (HVI) and Advanced Fibre Information System (AFIS). HVI and AFIS machines 
play a vital role in quality confirmation in a spinning mill. Without these machines, full quality work of a spinning industry will be incomplete. Before testing, fibres were conditioned. This was done to test the atmospheric condition. The test results of the two machines are provided below:

Table 1: Fibre properties

\begin{tabular}{|c|c|c|c|}
\hline \multicolumn{2}{|c|}{ HVI } & \multicolumn{2}{c|}{ AFIS } \\
\hline Properties & Values & Properties & Values \\
\hline SCI & 129 & NEP $($ Cnt/g) & 190 \\
\hline Moisture (\%) & 6.8 & NEP Size (um) & 776 \\
\hline Mic Value & 4.7 & SCN $(\mathrm{Cnt} / \mathrm{g})$ & 13 \\
\hline Maturity Ratio & 0.9 & SCN $(\mathrm{um})$ & 1089 \\
\hline UHML (mm) & 28.34 & SFC $(\%)$ & 7.2 \\
\hline UI (\%) & 82.9 & UQL (mm) & 30.3 \\
\hline SFI (\%) & 8.6 & $5 \%(\mathrm{~mm})$ & 34.5 \\
\hline Strength (GPT) & 29.9 & Fineness (mtex) & 172 \\
\hline Elongation (\%) & 5.5 & IFC (\%) & 4.1 \\
\hline
\end{tabular}

Two different yarns were produced in ring spinning systems using two (2) different traveller brand named Lakshmi Ring Travellers (LRT) and XAXIS. A C-shape traveller was used to produce both yarns. The yarn count of "30" Ne" KH (Card Hosiery) was produced in both systems. The count of roving was $0.80 \mathrm{Ne}$ and the same roving was fed to each spindle of ring frame so that variation can remain less. Moreover, all samples are produced with the same parameters such as traveller number, draft, spindle speed, number of twist per inch, etc. in two systems. Major parameters of ring frame are given in Table 2.

Table 2: Processing parameters of the ring frame

\begin{tabular}{|c|c|c|}
\hline Parameters & LRT & X-AXIS \\
\hline Break Draft & 1.12 & 1.12 \\
\hline Total Draft & 38 & 38 \\
\hline Spindle Speed & 15544 & 15544 \\
\hline TPI & 19.92 & 19.92 \\
\hline Traveller No. & $3 / 0$ & $3 / 0$ \\
\hline
\end{tabular}

After collection of the sample from ring frame, it was conditioned to test all the parameters of yarn. The properties of yarn such as evenness and hairiness were carried out in Uster Evenness Tester 5. Test speed of evenness tester was $400 \mathrm{~m} / \mathrm{min}$ and the test time took 1 minute for each test. During the production of yarn from roving in the ring section, end breakage study was accomplished through the whole doff. After that, all test results were procured to evaluate the statistically significant difference between two systems. Paired t-test was carried out in Microsoft Excel 2013 which revealed unevenness percentage, imperfection index, and hairiness test results. 
Table 3: Yarn properties and end breakage results

\begin{tabular}{|c|c|c|c|c|c|c|c|c|}
\hline $\begin{array}{c}\text { Brand } \\
\text { Name }\end{array}$ & $\begin{array}{c}\mathbf{U}_{\mathbf{m}} \\
(\mathbf{\%})\end{array}$ & $\begin{array}{c}\text { Imperfectio } \\
\text { n Index (-) }\end{array}$ & $\begin{array}{c}\text { Hairines } \\
\mathbf{s}(-)\end{array}$ & $\begin{array}{c}\text { Hairiness } \\
\mathbf{C V}(\boldsymbol{\%})\end{array}$ & $\begin{array}{c}\mathbf{S H} \\
\mathbf{( - )}\end{array}$ & $\begin{array}{c}\mathbf{S H}_{\mathbf{1}} \\
\mathbf{m}(-)\end{array}$ & $\begin{array}{c}\mathbf{S H}_{\mathbf{3}} \\
\mathbf{( - )}\end{array}$ & $\begin{array}{c}\text { End } \\
\text { Breakage } \\
\text { Rate/100 } \\
\text { Spindle-Hr. }\end{array}$ \\
\hline LRT & 11.66 & 482.18 & 5.27 & 1.31 & 1.21 & 0.16 & 0.10 & 15.02 \\
\hline X-AXIS & 11.57 & 469.41 & 5.31 & 1.70 & 1.22 & 0.2 & 0.12 & 17.05 \\
\hline
\end{tabular}

\section{Results and Discussions}

\section{Yarn Unevenness Results}

Unevenness is an important statistical tool for the measurement of evenness properties of spun yarn. Co-efficient of variation of mass is used largely in the whole world by textile technologists. Nevertheless, unevenness percentage of mass is also widely used side by side. It is observed from Figure 1 that unevenness value is higher in LRT than X-AXIS. It may be predicted that X-AXIS traveller has a smoother finish which helps for stable running and less heat generation. More so, the yarn contact area and ring contact area in the traveller is closer and this makes fibre lubrication better in cotton yarn. Therefore, the unevenness percentage value is superior in yarn made from XAXIS traveller than LRT traveller.

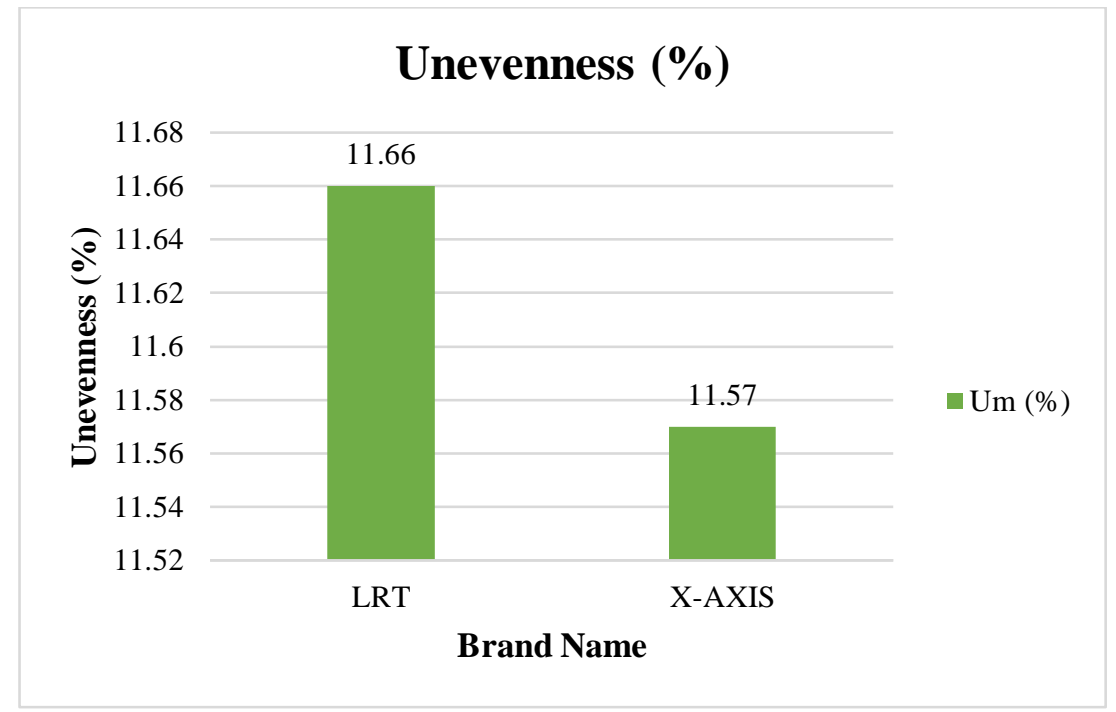

Figure 1: Unevenness properties of the yarn

\section{Yarn Imperfection Results}

Imperfection index is the summation of thin place $(-50 \%)$ per kilometer, thick place $(+50 \%)$ per kilometer, and nep $(+200 \%)$ per kilometer. Among the four thresholds of thin, thick place and neps per kilometer, they are usually selected for ring spun yarn. It is a good indicator of the yarn quality that shows how this yarn will perform in the subsequent process such as weaving, knitting, dying or printing, etc. Imperfection index remains in a 
greater position in LRT, whereas it is lower in X-AXIS. The possible explanation is that LRT traveller has less clearance and traveller finish. The ring traveller contact area is also very small (point contact) than X-AXIS. This is why imperfection results are bigger in LRT than X-AXIS.

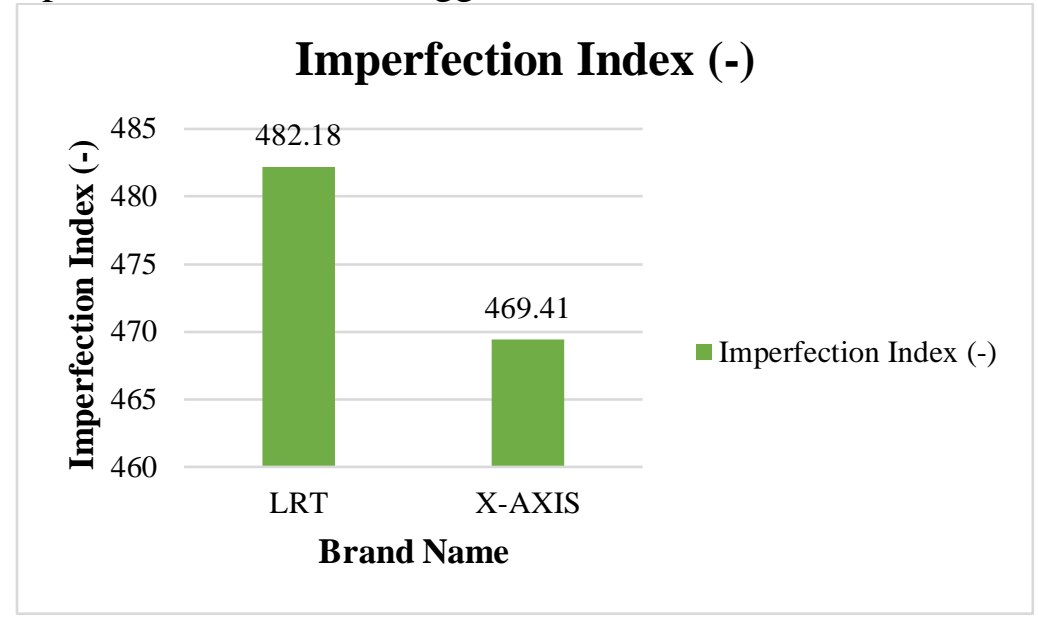

Figure 2: Imperfection index in yarn

\section{Yarn Hairiness Results}

Hairiness means the summation of the length of all projecting fibres in yarn body. One of the important factors for the comfortability of end product, especially apparel, is hairiness. Therefore, it is an essential property of yarn which has a great impact on the product. It is seen from Figure 3, 4, 5, 6, and 7 that the value of hairiness, coefficient of variation of hairiness, the standard deviation of hairiness, the standard deviation of hairiness in reference length 1 meter, and the standard deviation of hairiness in reference length 3 meters is larger in X-AXIS than LRT. It may be assumed that X-AXIS traveller has lightweight, low bow height than LRT traveller, and heat dissipation properties is also less (Technical Manual of "Lakshmi Ring Travellers (LRT)"). For these reasons, hairiness, the standard deviation of hairiness, the standard deviation of hairiness in reference length 1 meter, and the standard deviation of hairiness in reference length 3 meters is higher in yarn produced by using X-AXIS traveller. 


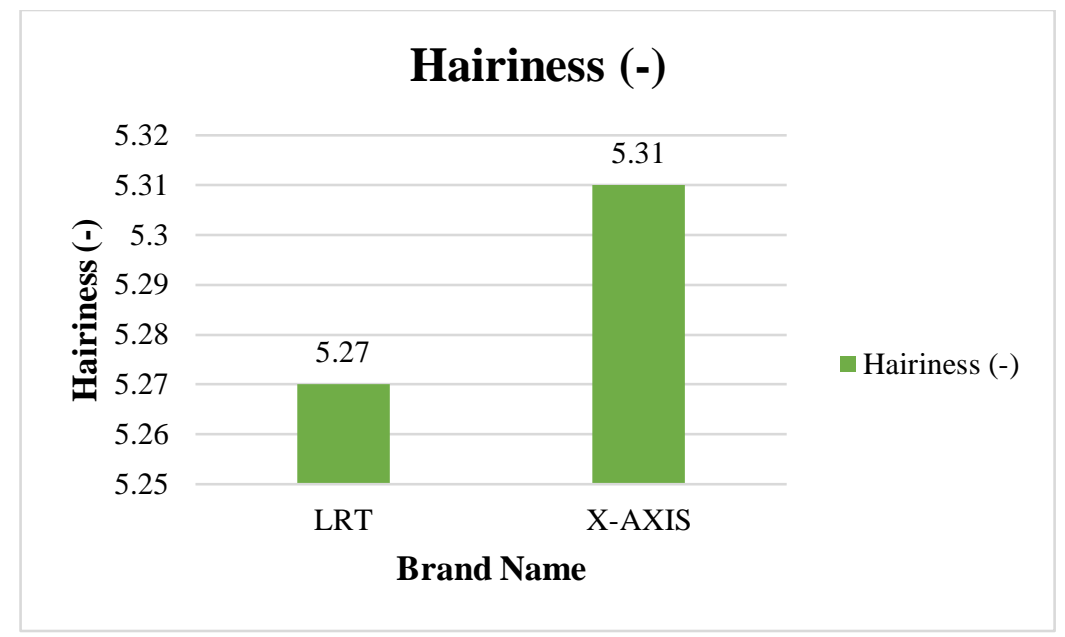

Figure 3: Hairiness of yarn

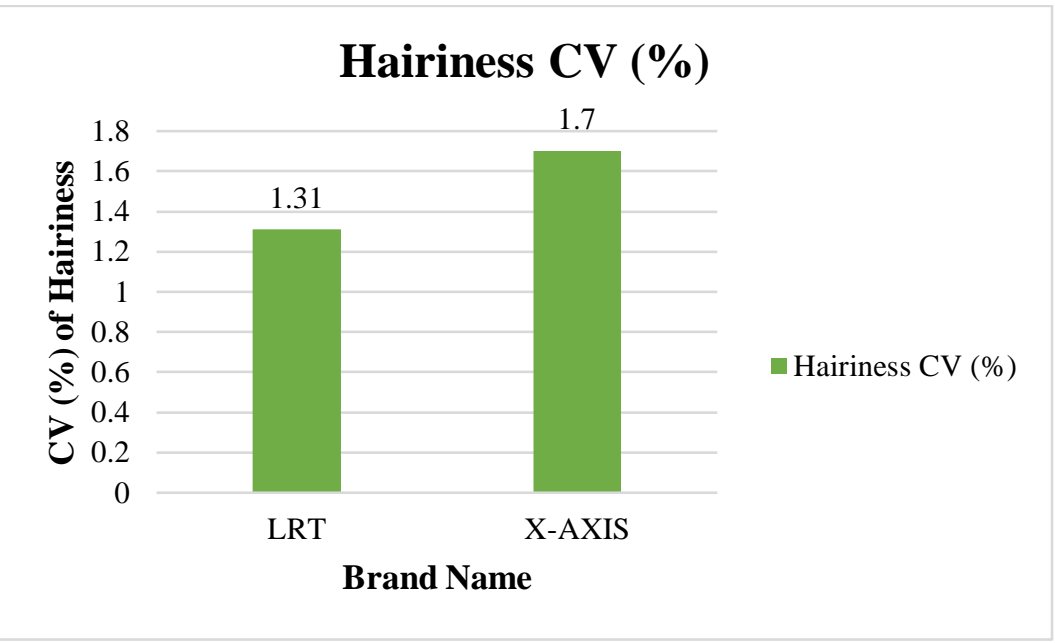

Figure 4: Coefficient of variation of hairiness of yarn 


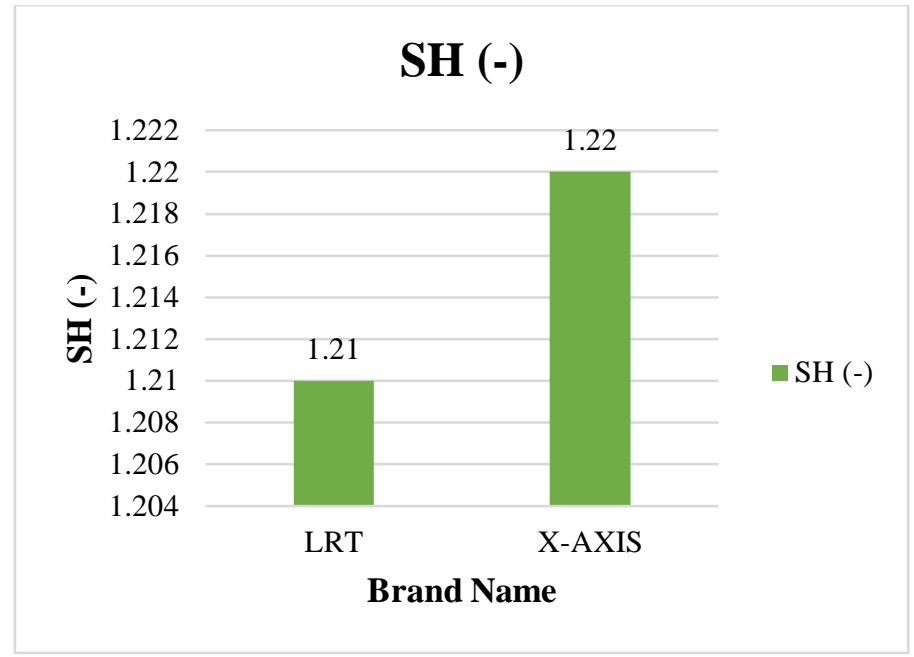

Figure 5: The standard deviation of hairiness of yarn

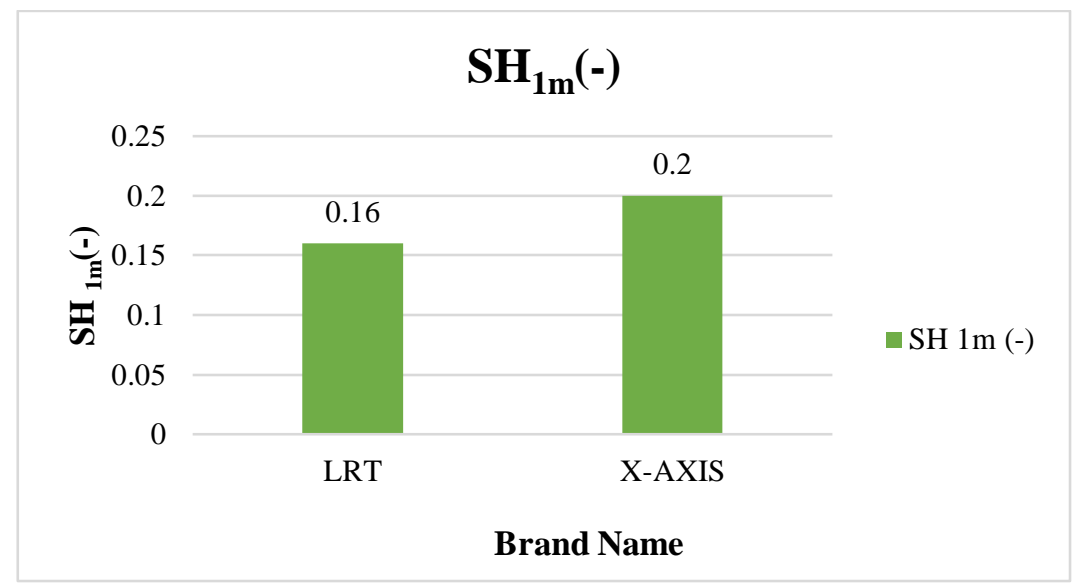

Figure 6: The standard deviation of hairiness of yarn with cut length 1 meter

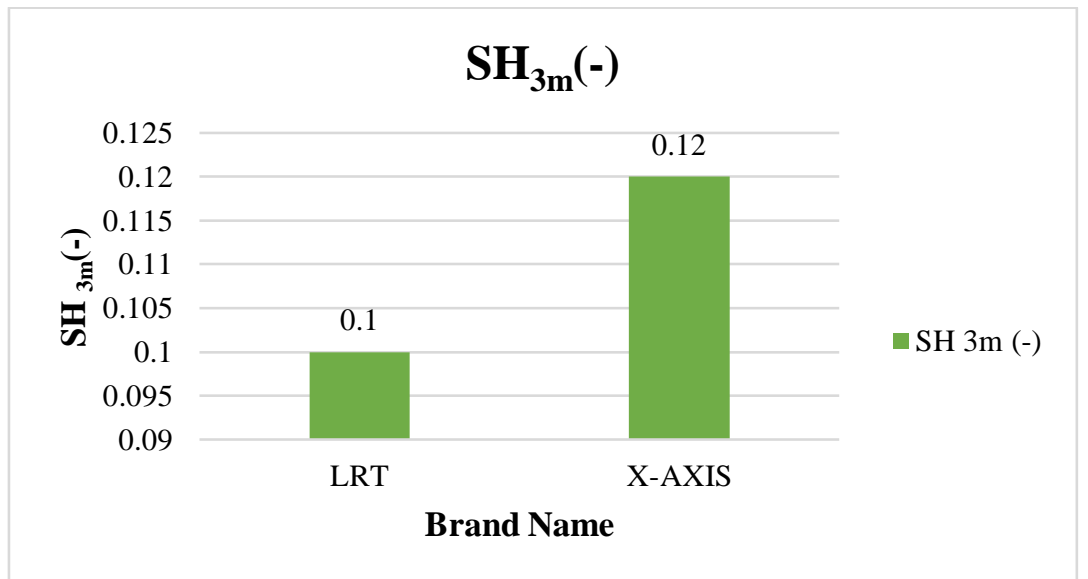

Figure 7: The standard deviation of hairiness of yarn with cut length 3 meters 


\section{End Breakage Results}

End breakage is totally unexpected to produce any kind of yarn. It is normally calculated in ring section per 1000/100 spindle per hour. End breakage means a fault in yarn, and it has several effects in the quality of yarn. It increases the amount of wastage, decreases productivity, intensification of fly generation which gives rise to yarn faults, reduction of machine efficiency, a decline of worker's efficiency, more cut in winding section, and a huge amount of wastage in winding section. Furthermore, it is observed from Figure 8 that the end breakage rate is more in X-AXIS than LRT. Hence, it is presumed that due to the light weight of X-AXIS traveller, the coefficient of friction between traveller/ ring is high which causes larger end breakage rate than LRT (Eric Oxtoby, 1987, p.122).

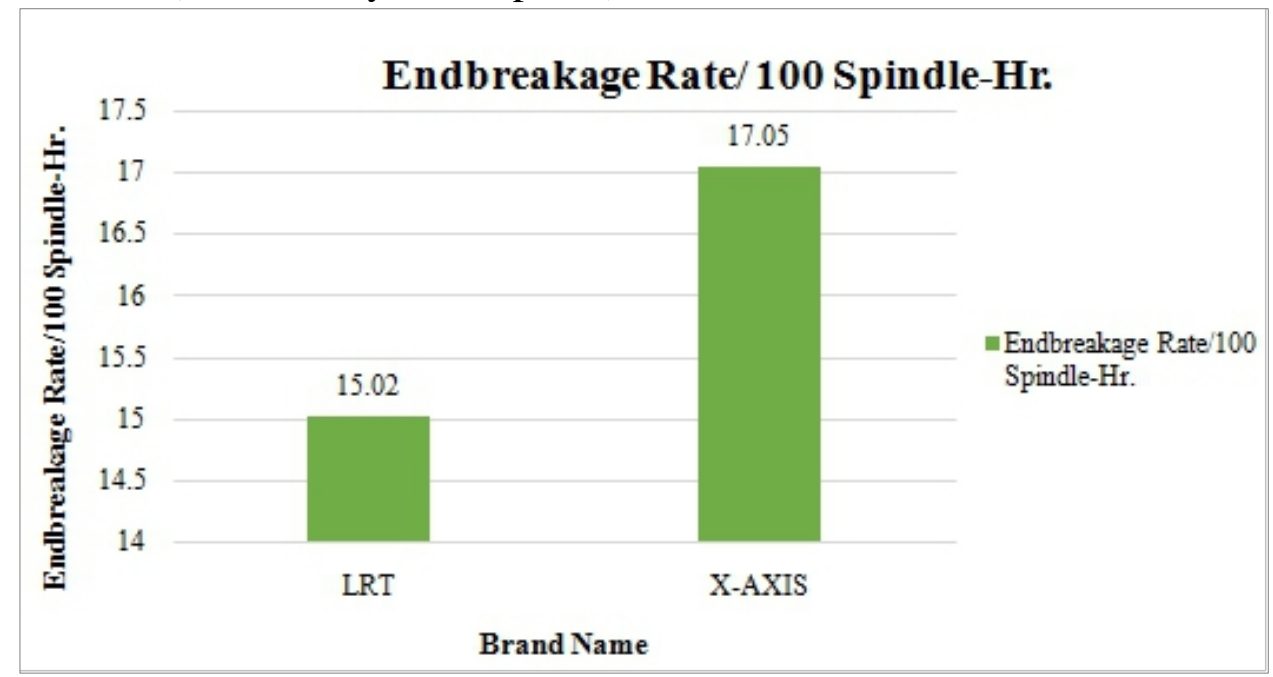

Figure 8: End breakage rate of yarn

\section{Statistical Analysis}

Pearson's correlation was carried out to determine the relationship between three properties named unevenness (\%), imperfection index (-), and hairiness (-) of yarn manufactured by using traveller of two brands similar to LRT and X-AXIS. The Pearson correlation coefficient value $\left(0.604-\mathrm{U}_{\mathrm{m}}\right.$ percentage, 0.659-imperfection index, and 0.799-Hairiness) indicates that there is a strong positive correlation in unevenness and imperfection index. There is also a very strong positive correlation in hairiness of two systems. Therefore, it is necessary to accomplish a significance test to decide, whether based upon this sample, if there is any or no evidence to suggest that negative correlation is present in the population.

A null hypothesis, $\mathrm{H}_{0}$, which indicates that there is no correlation in the population, is tested against the alternative hypothesis, $\mathrm{H}_{1}$, which reveals 
if there is a correlation. The data obtained will indicate which of these opposing hypotheses is most likely to be true. It can thus express this test as:

$\mathrm{H}_{0}: \rho=0$

$\mathrm{H}_{1}: \rho \neq 0$

It is observed from Table 4 that $t$ statistics value surpasses the $t$ critical one- tail and t critical two-tail value for two properties such as unevenness and hairiness except for imperfection index. This means that t-test is significant, and the two groups are statistically significantly different. On the other hand, imperfection index has no statistically significant difference between the values of two systems. The p-value for one-tail and a two-tail test is less than 0.05 for unevenness and hairiness properties excluding imperfection index. That implies that there is no significant difference in the means of each sample. The $\mathrm{p}$-value in the case of imperfection index exceeds the significant levels which indicate that there is a significant difference between two brands.

Table 4: t-test: paired two samples for means

\begin{tabular}{|c|c|c|c|}
\hline Parameters of t-test & $\mathbf{U}_{\mathbf{m}} \mathbf{( \% )}$ & Imperfection Index (-) & Hairiness (-) \\
\hline Pearson Correlation & 0.604 & 0.659 & 0.799 \\
\hline Hypothesized Mean Difference & 0 & 0 & 0 \\
\hline df & 17 & 17 & 17 \\
\hline t Stat & 3.014 & 1.655 & -3.936 \\
\hline $\mathrm{P}(\mathrm{T}<=\mathrm{t})$ one-tail & 0.004 & 0.058 & 0.001 \\
\hline $\mathrm{t}$ Critical one-tail & 1.740 & 1.740 & 1.740 \\
\hline $\mathrm{P}(\mathrm{T}<=\mathrm{t})$ two-tail & 0.008 & 0.116 & 0.001 \\
\hline $\mathrm{t}$ Critical two-tail & 2.110 & 2.110 & 2.110 \\
\hline
\end{tabular}

\section{Conclusion}

Lakshmi Ring Travellers (LRT) demonstrates better results than XAXIS ring travellers. This is due to the structure, materials properties, and weight of traveller. Unevenness and imperfection index properties are better in X-AXIS traveller, whereas hairiness, the standard deviation of hairiness in reference length 1 meter, the standard deviation of hairiness in reference length 3 meters, and end breakage rate is superior in LRT brand. The result of unevenness and imperfection index is good in X-AXIS because the surface finish is smooth which leads to fewer wear out tendency, stable running condition, and a small amount of heat generation during processing. On the other hand, the value of hairiness, standard deviation of hairiness in reference length 1 meter, standard deviation of hairiness in reference length 3 meter, and end breakage rate is better in LRT. This is as a result of high bow height that permits easy dissipation of generated heat in traveller and less friction between 
ring and traveller due to the heavier weight. Thus, hairiness and end breakage rate is low. Therefore, traveller has a great impact on the hairiness and end breakage value of spun yarn. Conclusively, LRT is better than X-AXIS although unevenness and imperfection is superior in it.

\section{References:}

1. Akshay Kumar, Ishtiaque \& Salhotra (2003). Compact Spinning -A Critical Review, 2003 ASME International Mechanical Engineering Congress, Washington, D.C., November 15-21.

2. Eric Oxtoby (1987). Spun Yarn Technology: Conventional frame spinning machines. (pp. 121-122), England by Anchor-Brendon Ltd, Tiptree Essex.

3. Feng-Lei Zhou \& Rong-Hua Gong (2009). Manufacturing technologies of polymeric nanofibres and nanofibre yarns, Polymer International, Polym Int 57:837-845 (2008).

4. Harish, R.J., Kolte, P. P., Nadiger, V. G. \& Daberao, A.M. (2018). Effect of Machine Variables on Rotor Yarn Properties, Journal of the TEXTILE Association, March - April 2018, pp 377-383.

5. Klein, W. (2011-2012). Manual of Textile Technology: A practical Guide to Ring Spinning. (pp. 203), England, The Textile Institute, ISBN 0900739916.

6. Lawrence, C.A. (2010). Advances in yarn spinning technology:Overview of developments in yarn spinning technology. (pp. 22), New Delhi, Woodhead Publishing Limited.

7. Lawrence, C.A. \& Chen, K.Z. (2009). Textile Progress, RotorSpinning. Vol. 13 No. 4, pp-1.

8. Neeraj Niijjaawan \& Rasshmi Niijjaawan (2010). Modern Approach to Maintenance in Spinning: Tips to fine tune the spinning machinery. (pp. 423), India, Woodhead Publishing India Pvt. Ltd.

9. Pattabhiram, T.K. (1997). Essential Elements of Practical Cotton Spinning: Spinning. (pp. 150), Mumbai, New Delhi, Somaiya Publications Pvt. Ltd.

10. Zheng-Xue \& Xungai Wang (2004). Distribution of Power Requirements During Yarn Winding in Ring Spinning, Textile Research Journal, 74(8). 735-74; (2004).

11. Technical Manual of "Lakshmi Ring Travellers (LRT). 